\title{
Efficacy of inspirational motivation on the performance of public health workers in mid- north of Uganda
}

\author{
Emmanuel Komakech $^{1 *}$, Gilbert Obici $^{2}$, David Mwesigwa ${ }^{3}$ \\ Discipline of Business Management, Faculty of Business and Management Sciences, Lira \\ University, Lira, Uganda ${ }^{1 *}$ \\ Discipline of Public Administration and management, Faculty of Business and \\ Management Sciences, Lira University, Lira, Uganda ${ }^{2,3}$ \\ komakeche45@gmail.com $^{l^{*}}$, obicigilbert89@gmail.com ${ }^{2}$, dmwesigwa@lirauni.ac.ug ${ }^{3}$
}

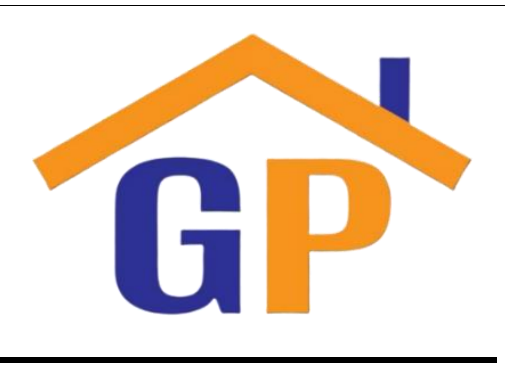

Article History

Received on 5 March 2021

$1^{\text {st }}$ Revision on 7 April 2021

$2^{\text {nd }}$ Revision 14 April 2021

Accepted on 14 April 2021

\begin{abstract}
Purpose: This study sought to determine the efficacy of inspirational motivation on the performance of middle-level Public Health Workers (PHWs) in Lira District Local Government. Specifically, the study aimed to: determine the degree of inspirational motivation among ML-PHWs in Lira District; determine the level of performance among ML-PHWs in Lira District; and investigate the effect of inspirational motivation on the performance of ML-PHWs in Lira District.
\end{abstract}

Research methodology: The study adopted a cross-sectional survey design while incorporating both quantitative and qualitative methods. The study used stratified and simple random sampling procedures to select health facilities, supervisors and ML-PHWs; a total of 164 respondents were selected.

Results: The findings suggest that inspirational motivation has a significant effect on the performance of ML-PHWs $(p<0.01)$.

Limitations: This study only focused on one construct of transformational leadership style (inspirational motivation), yet there are several constructs of that style, which may affect the performance of PHWs.

Contribution: The findings of this study can be useful to public service managers wishing to enhance the performance of PHWs using limited resources.

Keywords: Inspirational motivation, The performance of PHWs, Public health, Leaders

How to cite: Komakech, E., Obici, G., \& Mwesigwa, D. (2021). Efficacy of inspirational motivation on the performance of public health workers in mid-north of Uganda. Annals of Human Resource Management Research, 1(2), 85-97.

\section{Introduction}

Globally, there is a performance crisis in the public service as there is a need to produce more for less. This economic challenge, which strikes both developing and developed countries alike, raises the appetite for efficiency and effectiveness (Barasa, 2015). As a consequence, there is a need for evaluation mechanisms that aim to aid in assessing the performance of government programs that have proved inadequate over a long period of time. In the recent past, styles of leadership have been investigated by social scientists (Khuwaja, 2020) and it has gained prominence as a modern method for handling employees and the organisation as a whole. The growth of leadership styles and how each affects the performance of PHWs is traceable from as early as the $17^{\text {th }}$ century (Islam \& Rahman, 2020). From the close of the $17^{\text {th }}$ century, employees began undergoing diverse treatments, from being considered as equipment to being considered social beings for the drive to accomplish the set targets 
and intentions of an organisation (Islam \& Rahman, 2020). In Africa, the dynamic business environment of modern organisations has mounted a more significant challenge in facilitating less-performing employees to enhance their performance in a more and more casual domain as well as aiding every employee to become more effective at the workplace. It is clear that countless organisations are on the lookout for modern methods and techniques of expansion, particularly in the managerial components, which can support them in realising success (Wammy, 2014; Khuwaja, 2020).

It is noted that if business efficiency and economic development are to be achieved, organisations need to adopt various styles of leadership such as transformational, laissez-faire, autocratic and transactional (Wammy, 2014). This is so because every leadership style plays a role in motivating PHWs, controlling, managing, solving conflicts, and influencing them. This suggests that appropriate adaptation of a particular style of leadership depends on the culture and context, which vary from one setting to another (Ohunakin, Adeniji, Oludayo, Osibanjo \& Oduyoye, 2019). In spite of the efforts by the government of Uganda to design a system of assessing the performance of Local Government PHWs so as to establish adherence to the requirements for budgeting and accountability as well as providing incentives to improve performance, service delivery in Lira District is still wanting (ACODE, 2014). The Uganda National league table Report of the Ministry of Health for the financial years 2014/15, 2015/ 16 and 2016/17 indicates poor performance for the district in terms of percentage drop-in service delivery (Ministry of health, 2019). Consequently, PHWs cannot achieve set targets and support the line Ministry of Health in meeting the overall performance targets. These gaps may be due to a shortage of strategic interventions of specific constructs employed by the administrators. Besides, there is barely any documentation on the effect of a specific style of leadership on the performance of PHWs in Lira District. Therefore, this study was undertaken to examine the effect of the transformational style of leadership, specifically inspirational motivation, on the performance of ML-PHWs in Lira District Local Government.

Leadership within the health sector has been described as marshalling, persuading and sharing the vision of the organisation with a view of inspiring, motivating and empowering PHWs to work with a view of accomplishing a common purpose (Haase \& Franco, 2020). As a result, effective leadership necessitates professional abilities since the dearth of which can cripple that organisation in a number of ways. In this study, one construct of transformational style of leadership (inspirational motivation) is taken as an independent variable and the performance of employees as the dependent variable. Transformational leadership is a style of leadership used across the spectrum of politics, health, education, entertainment, finance, technology, and the industry. The transformational leadership style, namely empathy, importance of collective identity, risk-taking, kindness, relationship building, and goal articulation, has proved to be essential in many organisations. This style of leadership is dependent on encouraging and motivating followers to take part in shaping a successful future for an organisation (Islam, Rahman, \& Siddiqui, 2019). Also, this style of leadership embraces the establishment of a common purpose for the group, a concept embedded in the official "vision" and "mission of an organisation. In fact, the two aspects have become instrumental in helping leaders define and outline organisations' goals and objectives. A case in point, using transformational leadership can facilitate an organisation to guide junior staff to become enthused as they see how much they are recognised and appreciated in supporting both the organisation's long-term and short-term goals (Faiza, Longbao, Mohammad, \& Qazi, 2019). The components of transformational leadership are: intellectual stimulation which aims to boost PHWs ingenuity as well as invention, to inspire and support them; inspirational motivation, which aims to present a vibrant vision and give junior staff thought-provoking errands. Perse, in transformational leadership, leaders appeal as well as serving as good examples which can come up with creativities. Transformational leadership has been presented as an appropriate means to achieving individual transformation and the whole organisation in the face of dynamic situations, thus calling for learning to aid espousal, transforming the philosophy of an organisation.

In Uganda, Public health facilities are managed by a group of hospital administrators under the stewardship of the Medical Superintendent. According to Mukundane, Nannungi and Bataringaya (2016), the Medical Supervisor works closely with the core team of hospital administrators. Latest studies reveal that weak public health systems have characterised health service delivery in Uganda 
despite the numerous health sector reforms and policies aimed to improve the functioning and performance of the sector as well as the health status of the population (Bahendeki, Mutungi, Tugumisirize, Kamugisha, Nyangabyaki, Wesonga, Sseguya, Mubangizi, Nalunkuma \& Were, 2019). The Uganda National league table Report obtained from the Ministry of Health for financial years 2014/15, 2015/16 and 2016/17 exposes poor performance for Lira District, occasioning a percentage drop in health service delivery (see table 1 below).

Table 1. National league report for the period 2014-2017

\begin{tabular}{lccc}
\hline Indicators & $\mathbf{2 0 1 4 / 2 0 1 5}$ & $\mathbf{2 0 1 5 / 2 0 1 6}$ & $\mathbf{2 0 1 6 / 2 0 1 7}$ \\
\hline Immunization (PCV 3) & $99.9 \%$ & $95.6 \%$ & $88.2 \%$ \\
$4^{\text {th }}$ Antenatal Visit & $38.2 \%$ & $43 \%$ & $34.7 \%$ \\
$2^{\text {nd }}$ Intermittent preventive treatment for & $58.2 \%$ & $51.3 \%$ & $48.9 \%$ \\
$\begin{array}{l}\text { pregnant mothers } \\
\begin{array}{l}\text { Deliveries by Government and PNFP } \\
\text { facilities }\end{array}\end{array}$ & $53.4 \%$ & $56.2 \%$ & $58.2 \%$ \\
$\begin{array}{l}\text { Position in National league table } \\
\text { 7 out of } 112 \\
\text { districts }\end{array}$ & $\begin{array}{c}45 \text { out of } 112 \\
\text { districts }\end{array}$ & $\begin{array}{c}48 \text { out of } 112 \\
\text { districts }\end{array}$ \\
\hline
\end{tabular}

Source: Ministry of Health (2019)

A study conducted by Oketch (2019) reveals high rates of absenteeism among health workers in Lira District, ranging from $27 \%$ to $70 \%$. It is possible that the style of leadership employed by supervisors could have had an effect on the degree of service delivery in the district. As a consequence, this study, examined how inspiration motivation affects the performance of middle line health workers in Lira District Local Government.

\section{Literature review and hypothesis development}

The SET was developed by a professional sociologist focusing on people and behaviour. According to the theory, every positive or negative activity derived from an organisation in the course of working conditions (encouraging or hostile) directly stimulates employees to respond in a certain way towards the organisation. This response may be affirmative or damaging based on the total behaviour of the organisation. Additional review on this theory reveals that power is an essential element of SET and is very significant to understanding the perception of employees towards the authority in an organisation (Islam \& Rahman, 2020). Many researchers argue that employees love to feel more dedicated to their job performance and encourage to take hold of the valuable work arrangement, from the perceived outcome towards authority and style of leadership (Islam, Rahman, \& Siddiqui, 2019). This exchange relationship is a significant factor to influence employee motivation at the workplace and to the work behaviour as a whole. The researchers in this study define authority in the form of leadership styles, which directs the performance of employees PHWs as an outcome behaviour. As a consequence, the context is considered based on the key concept of theory to reveal the relationship in the name of dependent variables (the performance of PHWs) and independent variable (inspirational motivation).

Style of leadership - Any organisation that employs an appropriate style of leadership(s) together with other factors, such as personal characteristics, has a higher prospect of achieving its organisational goals. An organisational style of leadership goes a long way to affecting the culture of an organisation. This condition affects the performance of an organisation (Akparep, Jengre, \& Alisa, 2019). Consequently, leadership is described as one of the key requirements of any organisation and its significance should never be underrated. Vito (2020) notes that a style of leadership is the method adopted by managers to suit as well as meet the varying organisational needs and priorities from time to time. This is observed to be an individual behaviour an organisational manager adopts with a view of inspiring employees to realise a defined target of that organisation. Studies (such as Akparep, Jengre, \& Alisa, 2019) suggest that leadership is a result of a number of behavioural qualities, know-how, assertiveness and thinking of the managers. This reveals that a leadership style has an impact on job satisfaction and the desire and intention of PHWs to leave an organisation. The various styles of leadership are; autocratic Style of leadership (ALS), bureaucratic Style of leadership (BLS) (Cwalina 
\& Drzewiecka, 2019), charismatic Style of leadership (CLS), democratic/Participative Style of leadership, Laissez-Faire Style of leadership (LLS) (Donkor \& Zhou, 2020), transactional Style of leadership, transformational Style of leadership (Manzoor, Wei, Nurunnabi, \& Subhan, 2019; Acquino, 2015).

A study by Henricks, Young and Kehoe (2020) reveals that transformational leadership comprises of four dimensions. First, the idealised effect is the degree to which groups realise the value of leaders, confidence, belief, power and ethical or moral orientation; their enthusiasm to ascertain these qualities; and a diversion from self-centredness to higher collective goals. Second, inspirational motivation describes how leaders articulate visions to stimulate and motivate subordinates to reach desired goals. Third, intellectual stimulation can refer to leaders who challenge the status quo and primary assumptions, encourage followers to do so, and are open to new and creative solutions to problems. The final dimension is individualised consideration, where leaders provide emotional support and consideration for each follower. Diverse circumstances call for diverse styles of leadership. The style should be one that most meets the objectives of the team while balancing the interest of its followers and team members of that group (Iqbal, Anwar \& Haider, 2015). However, this study focuses on one of three constructs of transformational leadership, specifically inspirational motivation.

\subsection{Employee performance}

The term performance describes the capacity of employees to use their acquaintance and skills proficiently and meritoriously. Thus far, the performance of employees is associated with his/her physical and educational achievement (Iqbal, Anwar \& Haider, 2015). In this respect, employees' performance is essential in realising the outcomes consistent with the universal principles. The performance of specific workers exclusively hinges on the procedures of the specific organisation in terms of salaries, recompenses, gratuities, annual percentage increase, and other incentives and honours (Baroudi, Tamim \& Hojeij, 2020). Also, the educational achievement of an employee is key amongst all other elements. On the whole, the productivity/output can be enhanced and sustained by the effectiveness of the leadership and an agile response of the employees (Zohra, Mukaram \& Syed, 2018). On the one hand, the leadership style induces emotional strength, motivation, commitment and the working relationship while on the other side; the employees perform with their utmost ability and diligence. The main attributes extracted from the relevant literature are efficiency, effectiveness, productivity, and timeliness. On the other hand, some other attributes are related to employees' performance like work ethics, communication, creativity, development, professionalism, and commitment. All of them contribute to the effective performance on the part of employees.

According to Chanda and Goyal (2020), assessment of an employee's performance involves the core responsibilities accomplished and the actions of the employee in a specific period in contrast with the objectives for the period. In addition, assessment embraces the value of actions, compliance with the anticipated ideals, the expected overheads, and the period taken in accomplishing the outcomes. Hamstra, Van Vianen and Koen (2019) note that assessing employee performance is the foundation of performance appraisal policies. Consequently, a precise and well-organised performance assessment not only forms the root of a precise performance appraisal but provides a means to judge the potential of an employee (Abramson, Resch, Ovsiew, White, Bernstein, Basurto \& Soble, 2020). According to Barnabe, Guercini and Di Perna (2019), assessing an employee's performance grounded on a single or some elements can be responsible for erroneous outcomes and leave a negative image on the teams and the general organisation. By assessing the actions of employees, an organisation may appraise a number of its workforces as exceptional, even if the organisation may have been unsuccessful in meeting its set targets.

\subsection{Inspirational motivation and the performance of employees}

A study by Ngaithe, K'Aol, Lewa \& Ndwiga (2016) examined the efficacy of inspirational motivation on the performance of staff among State Owned Enterprises (SOEs) in Kenya. The study used factor analysis to reduce data, correlation analysis to establish the relationship between staff performance and inspirational motivation, chi square test, Analysis of Variance (ANOVA) and multiple linear regression model to test the hypotheses. The study found that Inspirational motivation was positively and 
significantly related with staff performance and significantly predicted staff performance. Accordingly, the study concluded that inspirational motivation positively and significantly increased performance of staff in SOEs in Kenya. A separate study by Akeel (2014) considered the relationship between dimensions of transformational leadership and employee motivation in public sector organisations in Libya. The dimensions are idealised affect, inspirational motivation, individualised consideration and intellectual stimulation. A quantitative approach and a correlational research design were used in the study. Multiple regression analysis was applied to establish the relationship between selected constructs of transformational leadership and the performance of employees, which generated a significant relationship between the two variables. These constructs contributed $73.7 \%$ to the variance in the performance of employees. In addition, inspirational motivation contributed $6.4 \%$. In their study, Langat, Linge and Sikalieh (2019) investigated the effect of inspirational motivation on the performance of employees and established that the work correspondence of employees had a substantial moderating effect on the association between transformational leadership and the performance of lower-level managers. Each of the three studies cited above attest to the fact inspirational motivation is central in the performance of employees, hence, this study is hinged on the hypothesis that inspirational motivation has a significantly positive effect on the performance of employees in Lira district.

\section{Research methodology}

\subsection{Design and area of study}

This study adopted a case study design and was conducted in all the government health facilities in the District of Lira, located in Lango sub-region, mid-North of Uganda. The districts of Pader border it in the Northern part, Otuke in North - East, Alebtong in the Eastern part, Dokolo in the Southern part, Kole in the Western part, and Oyam and Gulu in the North-Western part. Lira District has one Higher Local Government, one Municipal Local Government (with 4 divisions) and 9 Sub-County Local Governments. However, by the beginning of the FY 2020/2021 the municipal council was elevated to a city council. Lira District has 31 health facilities with 1 regional referral hospital, 3 health centre IVs, 17 health Center IIIs and 10 health Center IIs distributed across the district. Out of 31 health facilities, 7 are private-not-for-profit (PNFP) health facilities and 24 are Government health facilities that provide free health care services to clients. Data were collected between August and December 2020.

\subsection{Study population}

The study population comprised the middle-level Public Health Workers (PHWs) within the various departments in health facilities of Lira District. They included supervisors/in-charges and middle-level PHWs (ML-PHWs). These were chosen because they are believed to be conversant with the different characteristics of inspirational motivation executed by their supervisors. A sample of 164 ML-PHWs out of the total population of 250 health workers was selected using Krejcie and Morgan (1970) formula:

$$
\begin{aligned}
& s=X^{2} N P(1-P) / d^{2}(N-1)+X^{2} P(1-P) \ldots \ldots \ldots \ldots \ldots \ldots \ldots \ldots \ldots \ldots \ldots \ldots \ldots \ldots \ldots \ldots \ldots \ldots \ldots \ldots \ldots \ldots \\
& \mathrm{X}^{2}=\text { the table value of chi-square for } 1 \text { degree of freedom at the desired confidence level } \\
& (3.841) ; \\
& \mathrm{N}=\text { the population size; } \\
& \mathrm{P}=\text { the population proportion (assumed to be } 0.50 \text { since this would provide the maximum } \\
& \text { sample size); } \\
& \mathrm{d}=\text { the degree of accuracy expressed as a proportion }(.05) .
\end{aligned}
$$

Table 2. Sample size determination

\begin{tabular}{llll}
\hline Population Category & Population & Sample & Sampling Technique \\
Health facility In- Charges & 30 & 28 & Purposive sampling \\
ML-PHWs (nurses, midwives, etc.) & 220 & 136 & Simple Random Sampling \\
Total & $\mathbf{2 5 0}$ & $\mathbf{1 6 4}$ & \\
\hline
\end{tabular}

Source: Primary data.

Table 2 above shows that more from ML-PHWs (136) than supervisors (28) were sampled using a simple random sampling technique (Shahzad, Al-Noor, Hanif \& Sajjad, 2020). However, the response 
rate was 113 representing $68.9 \%$, which is a good response seeing that much of the data was collected during Corona pandemic.

\subsection{Data collection procedures}

The researchers obtained a letter of introduction from the Faculty of Business and Management Sciences, Lira University. The researcher delivered the letter of request to complete the study to the District Health Officer of Lira District and obtained permission to carry out the study before visiting the study area. After seeking permission from the DHO of Lira District, appointment was made with the respondents and respective facility in-charges from each health facility. This was done two days before the actual data collection activities. Quantitative data were cleaned and questionnaires coded manually before entering the information into the STATA 14 . The questionnaires were kept under lock and key to avoid access by unauthorised persons.

\subsection{Data analysis}

The data were analysed using Statistical Package for Social Sciences (SPSS) version 23. Descriptive statistics were used to describe the details of the variables. Pearson Product Moment coefficient was used to indicate the direction and strength of the relationships. In contrast, probability (p) values were used to test the significance of each of the exploratory variables at alpha level of 5\%. Finally, the Linear Regression Model (LRM) was applied so as to determine the relative strengths of the relationship of the variable with respect to the performance of PHWs. The formula for multiple linear regression is:

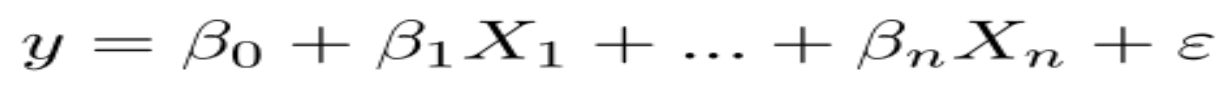

- $\mathbf{y}=$ the predicted value of the dependent variable, performance of PHWs,

- $\beta_{0}=$ the $\mathrm{y}$-intercept (value of The performance of PHWs when all other parameters are set to $0)$

- $\quad \beta_{1}=$ the regression coefficient of the first independent variable, individualised consideration.

- $\beta_{2}=$ the regression coefficient of the second independent variable, inspirational motivation.

- $\beta_{3}=$ the regression coefficient of the third independent variable, intellectual stimulation.

- $\quad \mathbf{e}=$ model error (a.k.a. how much variation there is in our estimate of the performance of PHWs)

\section{Results and discussions}

Background characteristics of the respondents

This section outlines the descriptive statistics calculated as obtained by the researchers included in the biographical questionnaire. The background variables take attention to gender, level of education, marital status and age group. The information on the respondents is summarised in table 3 below. The total number of respondents was 113, out of which the Majority (54.0\%) were female and $46.0 \%$ were male.

Table 3. Background characteristics of the respondents

\begin{tabular}{lcc}
\hline Variable & Frequency & Percent \\
\hline Gender & & \\
Female & 61 & 54.0 \\
Male & 54 & 46.0 \\
Total & 113 & 100 \\
Marital Status & & \\
Single & 13 & 11.5 \\
Married & 87 & 77 \\
Widowed & 10 & 8.8 \\
\hline
\end{tabular}




\begin{tabular}{|c|c|c|}
\hline Separated/Divorced & 3 & 2.7 \\
\hline Total & 113 & 100 \\
\hline \multicolumn{3}{|l|}{ Education Level } \\
\hline Primary & 2 & 1.8 \\
\hline Ordinary level & 33 & 29.3 \\
\hline A 'level & 17 & 15.0 \\
\hline Diploma & 42 & 37.2 \\
\hline Degree & 19 & 16.8 \\
\hline Total & 113 & 100 \\
\hline \multicolumn{3}{|l|}{ Gender of Supervisor } \\
\hline Male & 81 & 71.7 \\
\hline Female & 32 & 28.3 \\
\hline Total & 113 & 100 \\
\hline \multicolumn{3}{|c|}{ Education of Supervisor } \\
\hline Certificate & 7 & 6.2 \\
\hline Diploma & 40 & 35.4 \\
\hline Bachelor & 51 & 45.1 \\
\hline Postgraduate & 15 & 13.3 \\
\hline Total & 113 & 100 \\
\hline \multicolumn{3}{|l|}{ Age group } \\
\hline$<=30$ & 35 & 31.5 \\
\hline $31-40$ & 45 & 40.5 \\
\hline $41-50$ & 26 & 23.4 \\
\hline 51 and Above & 5 & 4.5 \\
\hline Total & 113 & 100 \\
\hline
\end{tabular}

Source: Primary Data (2020)

Regarding marital status, the majority $(77 \%)$ were dominated by the married while the least $(2.7 \%)$ were single. The majority (37.2\%) of the respondents had diplomas and the least (1.8\%) had primary education for education level. Regarding the supervisors' education, the majority $(45.1 \%)$ had Bachelor's degrees and the least (6.2\%) had certificates. Finally, most of the respondents (40.5\%) were in the age group $31-40$ years and the minority $(4.5 \%)$ were in the age group of 51 and above years.

\subsection{Empirical results of the study}

4.1.1. Descriptive Statistics on transformational leadership

Descriptive statistics were used to describe the level of inspirational motivation, specifically in terms of mean, standard deviation, and coefficient of variation as illustrated on table 4 below.

Table 4. Descriptive statistics on level of inspirational motivation

\begin{tabular}{lcrr}
\hline Items & Mean & Std. Dev & cv \\
\hline $\begin{array}{l}\text { My supervisor talks optimistically about the future } \\
\text { My supervisor expresses confidence that goals will be }\end{array}$ & 4.08 & .902 & .221 \\
achieved & 4.063 & .809 & .199 \\
$\begin{array}{l}\text { My supervisor talks enthusiastically about what needs to be } \\
\text { accomplished }\end{array}$ & 4.081 & .844 & .207 \\
$\begin{array}{l}\text { My supervisor talks optimistically about the future } \\
\text { Average }\end{array}$ & 3.991 & .934 & .234 \\
\hline
\end{tabular}

Source: Primary data, 2020.

Specifically, on a scale of 1-5, the average rating for inspirational motivation is 4.054 indicating a higher value for the variable. This implies that respondents agree that the level of inspirational motivation as 
practiced by supervisors in the Health sector of Lira district is high. The coefficient of variation for the item "My supervisor expresses confidence that goals will be achieved" $(\mathrm{CV}=0.199)$ is least indicating that this item was less dispersed and so respondents had less divergent views concerning the construct.

\subsubsection{Descriptive statistics on the performance of $P H W s$}

The level of performance was presented in terms of mean, standard deviation, and coefficient of variation for each of the three constructs (efficiency and effectiveness, productivity and timeliness) separately as indicated on tables 5 to 7 below.

Table 5. Summary statistics on efficiency and effectiveness

\begin{tabular}{llrr}
\hline Constructs & Mean & Std. Dev & cv \\
\hline I usually accomplish my duties effectively & 4.468 & .675 & .151 \\
$\begin{array}{l}\text { I usually offer competent and effective direction to the clients } \\
\text { My services in this facility contribute to the well-being of the }\end{array}$ & 4.495 & .631 & .14 \\
clients & 4.55 & .599 & .132 \\
I am always accountable for my mistakes & 4.333 & .778 & .18 \\
$\begin{array}{l}\text { I ensure safety, ethics and efficient use of data obtain from } \\
\text { clients }\end{array}$ & 4.36 & .736 & .169 \\
Average & $\mathbf{4 . 4 4 1}$ & $\mathbf{0 . 6 8 4}$ & $\mathbf{0 . 1 5 4}$ \\
\hline
\end{tabular}

Source: Primary data, 2020.

The results in table 5 reveal that every item had a mean $>3.00$, suggesting the above-average performance of these items. Overall, the average rating of productivity was 4.251 , indicating aboveaverage performance for the construct. This suggests that respondents agree with their status of productivity. The coefficient of variation for the item "My services in this facility contribute to the wellbeing of the clients" ( $\mathrm{CV}=0.132)$ is least indicating that this item was less dispersed. In other words, respondents had less divergent views that services in their facility contribute to the well-being of clients.

Table 6. Summary statistics on productivity

\begin{tabular}{lccl}
\hline Constructs & Mean & Std. Dev. & cv \\
I spend most of my time at work attending to the clients & 4.477 & .688 & .154 \\
My skills are suited for the type of work I do & 4.369 & .883 & .202 \\
I regularly participate in events like meetings, conferences and & 3.917 & 1.107 & .282 \\
seminars & & & \\
I usually spend most of my time guiding and counselling clients & 4.162 & .826 & .198 \\
I participate in collaborative projects within the facility & 3.991 & .928 & .233 \\
I participate in discussions that raise social responsibility & 4.171 & .862 & .207 \\
I feel happy when doing my job & 4.667 & .651 & .14 \\
Average & $\mathbf{4 . 2 5 1}$ & $\mathbf{0 . 8 4 9}$ & $\mathbf{0 . 2 0 2}$ \\
\hline
\end{tabular}

Source: Primary data, 2020.

The results reveal that all constructs had moderate means (mean $>3.00$ ), implying the above-average performance. Overall, the average rating of productivity was 4.251 , indicating above-average performance for this construct. This implies that respondents agreed with their status of productivity. The coefficient of variation for the item "I feel happy when doing my job" $(\mathrm{CV}=0.14)$ is least indicating that this item was less dispersed" $(\mathrm{CV}=0.154)$ is least, indicating that this item was less dispersed. In other words, respondents had less divergent views on this construct.

Table 7. Summary statistics on timeliness

\begin{tabular}{lccc}
\hline Constructs & Mean & Std. Dev. & cv \\
\hline I usually report and start my work in time & 4.387 & 0.677 & 0.154 \\
I regularly prepare my reports and accountability in time as & & & \\
required by my supervisors & 4.315 & 0.763 & 0.177 \\
I always end my daily duties at the right time & 4.243 & 0.917 & 0.216
\end{tabular}


Source: Primary data, 2020.

The results show that all items had moderate scores (all means $>3.00$ ), implying the above-average performance. Overall, the average rating of timeliness was 4.315 indicating above-average performance for this construct. This implies that respondents agreed that they performed their duties timely. The coefficient of variation for the item "I usually report and start my work in time" (CV=0.154) is least indicating that this item was less dispersed. In other words, respondents had less divergent views on this item.

Table 8. Robust Regression for predicting the performance of PHWs

\begin{tabular}{|c|c|c|c|c|c|c|c|}
\hline Performance & Coef. & St. Err. & t-value & p-value & $\begin{array}{l}{[95 \%} \\
\text { Coef. }\end{array}$ & Interval] & Sig. \\
\hline \multicolumn{8}{|l|}{ Inspirational } \\
\hline Motivation & 0.144 & 0.054 & 2.66 & 0.009 & 0.037 & 0.252 & $* * *$ \\
\hline (Constant) & 3.080 & 0.211 & 14.62 & 0.000 & 2.662 & 3.499 & $* * *$ \\
\hline Mean dependent var. & & 4.337 & SD dep & adent var. & & 0.465 & \\
\hline Adj. R-squared & & 0.331 & Numbe & of obs. & & 96.000 & \\
\hline F-test & & 15.203 & Prob. > & & & 0.000 & \\
\hline
\end{tabular}

A robust regression analysis was carried out to establish the degree of effect of Inspirational Motivation constructs on the performance of PHWs. It was found that inspirational motivation $(\mathrm{p}<0.001$, $\beta=0.144$ ) are significant predictors of The performance of PHWs. Inspirational motivation explains $33.1 \%$ of all the possible factors that are likely to account for the performance of middle level PHWs in Lira District (Adj. $\mathrm{R}^{2}=0.331$ ). This indicates $33.1 \%$ variability in the performance of PHWs in Lira District even after taking a number of predictor variables. The fact that the simultaneous variation of independent variables explains the performance of PHWs to the extent of 33.1\%, an increase in 0.190 scores in performance of PHWs for every unit increase in intellectual stimulation, assuming all other variables in the model are held constant. Similarly, an increase in 0.144 score in performance of PHWs for every unit increases in inspirational motivation assuming all other constructs in the model are held constant.

\subsubsection{Relationship between inspirational motivation and the performance of PHWs}

The study used Pearson product-moment correlation analysis to establish the strength of the relationship between transformational leadership construct and the performance of PHWs; the results are illustrated in table 9 below.

Table 9. Pairwise correlations of inspirational motivation

\begin{tabular}{lllll}
\hline Variables & $(1)$ & $(2)$ & $(3)$ & $(4)$ \\
\hline $\begin{array}{l}\text { (1) The performance of PHWs } \\
\text { (3) Inspirational motivation }\end{array}$ & 1.000 & & & \\
* significance at the 0.05 level & & $0.851^{*}$ & & 1.000 \\
\hline
\end{tabular}

Source: Primary data, 2020.

The results reveal that the performance of PHWs is positively and significantly correlated to inspirational motivation $(r=0.527, \mathrm{p}<0.05)$, thus suggesting that an increase in inspirational motivation scores leads to an increase in the performance of PHWs. Inspirational motivation $(r=0.374, p<0.05)$ is positively and significantly associated with the performance of PHWs $(r=0.474, p<0.05)$. This suggests that a unit increase in inspirational motivation will have a significant increase in the performance of PHWs in Lira city. 


\subsubsection{Regression Analysis for predicting the performance of PHWs}

A multivariate regression model was applied to determine the relative importance of inspirational motivation with respect to the performance of PHWs. Precisely, regression analysis was performed to estimate the amount of increase in the performance of PHWs that a unit increase will influence in the constructs of inspirational motivation. Before running Linear regression analysis, three assumptions were tested for reliable estimation of parameters: Normality of Residuals, Homoscedasticity of Residuals and Multicollinearity.

\subsubsection{Normality of residuals}

Normality of the residuals was tested using the Shapiro-Wil W test and the results reveal that it is very small ( $\mathrm{p}<0.001)$, suggesting that we can reject that $\mathrm{r}$ is normally distributed (see table 10 below).

Table 10. Shapiro-Wilk W test scores

\begin{tabular}{lccccc}
\hline Variable & Obs. & $\mathrm{W}$ & $\mathrm{V}$ & $\mathrm{z}$ & Prob.>z \\
Resid. & 104 & 0.919 & 6.895 & 4.292 & 0.000 \\
\hline
\end{tabular}

Source: Primary data, 2020.

\subsubsection{Homoscedasticity of residuals}

The non-graphical test was used to check if the variance of the residuals is homogenous. The results indicate that the p-value is very small, thus rejecting the hypothesis and accepting the alternative hypothesis that the variance is not homogenous. Also, the evidence is against the null hypothesis for heteroscedasticity that the variance is homogeneous (see table 11).

Table 11. Breusch-Pagan / Cook-Weisberg test for heteroscedasticity

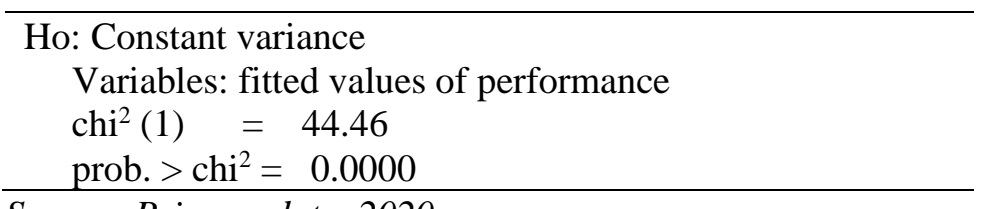

Source: Primary data, 2020.

4.1.4.3. Checking for multicollinearity

The Variance Inflation Factor (VIF) was used to test for multicollinearity; given that VIF > 5, there is an indication that multicollinearity is present; with VIF $>10$ there is multicollinearity among the variables. As a result, all the constructs of inspirational motivation had low VIF values suggesting that they are not redundant, and as such, an ordinary least square regression is plausible.

Table 12. Variance inflation factor

\begin{tabular}{lrr}
\hline Variables & VIF & $1 /$ VIF \\
Inspirational Motivation & 1.278 & .782 \\
Mean VIF & 2.701 &. \\
\hline
\end{tabular}

Source: Primary data, 2020.

\subsubsection{Checking for influential data}

The partial-regression plot was used to identify influential points. The plot reveals how the observation for Inspirational motivation affects the coefficient since the regression line is tagged upwards trying to fit through the extreme values. From the diagnostic, the assumption of normality and influential data are not met; therefore, results of ordinary least square regression are not reliable. If OLS is used, it will compromise the validity of the regression results since it is not robust to violations of its assumptions.

\subsection{Discussion of findings}

This study aimed to establish the effect of inspirational motivation on the performance of PHWs in Lira District. From the findings of this study, it is revealed that a positive relationship exists between the two variables. This is revealed by the statistics illustrated above. In fact, the results suggest that any 
improvement in inspirational motivation by a single unit will have a direct and proportional outcome in the level of motivation in the same direction. Consequently, the study found that inspirational motivation had a significant effect on the performance of PHWs, which is consistent with the outcomes of a study conducted by Ngaithe and K'Aol, (2016) in Kenya. The study found that inspirational motivation was positively and significantly associated with the performance of PHWs and significantly predicted staff performance. A similar study by Akeel (2014) sought to establish that the relationship between inspirational motivation and the performance of PHWs was found to be non-significant. Langat, Linge and Sikalieh (2019) equally investigated the effect of inspirational motivation on the job performance of PHWs and established that inspirational motivation significantly predicted the job performance of PHWs. Also, the findings agree with Mishra (2020), whose study established that all the four dimensions of transformational leadership, that is, idealised influence, inspirational motivation, intellectual stimulation, and individualised consideration, yielded a positive and significant relationship with reliable organisational efforts, including the thrust to raise the performance of employees. The study finds that some of the ideas raised in the Social Exchange Theory suggesting that every positive or negative activity derived from an organisation in the course of work (be they encouraging or hostile) has a direct stimulus on the performance of PHWs in an organisation.

\section{Conclusion}

This study was based on three key objectives, which sought to determine the degree of inspiration motivation, the degree of the performance of PHWs and the effect of inspirational motivation on the performance of PHWs. The findings indicate that inspirational motivation significantly affects the performance of PHWs in Lira District, concluding that once an organisational manager adopts transformational leadership by emphasising inspirational motivation, the performance of PHWs will improve.

\section{Limitation and study forward}

This study only focused on one construct of transformational leadership style (inspirational motivation), yet there are several constructs of that style, which may affect the performance of PHWs. Consequently, it is recommended that other studies can be conducted to establish the effect of other constructs of transformational leadership style on the performance of PHWs. Besides, the formal training of healthcare managers can be reinforced by implementing a leadership mentorship programme where they are provided with constant feedback on their behaviour and how they can link to these qualities that foster effective and proactive transformational leadership behaviour.

\section{References}

Abramson, D.A., Resch, Z.J., Ovsiew, G.P., White, D.J., Bernstein, M.T., Basurto, K.S., and Soble, J.R. (2020). Impaired or invalid? Limitations of assessing performance validity using the Boston naming test. Applied neuropsychology: Adult. Doi: 10.1080/23279095.2020.1774378

ACODE . (2014). Lira District Council Score-Card Report 2012/2013.

Acquino. (2015). The effectiveness of leadership styles of managers and supervisors to employees job satisfaction in cooperative organisations in the Philippines. The Macrotheme Review, 4, 1828.

Akeel, B. A. (2014). the role of transformation style of leadership in motivating public sector employees in Libya. Australian Journal of Basic and Applied Sciences, 7(2), 99-108.

Bahendeke, S., Mutungi, G., Tugumisirize, F., Kamugisha, A., Nyangabyaki, C., Wesonga, R., Sseguya, W., Mubangizi, D., Nalunkuma, C., \& Were, T.P. (2019). Healthcare delivery for paediatric and adolescent diabetes in low resource settings: type 1 diabetes clinics in Uganda. Global public health, 14 (12). 1869-83. Doi: 10.1080/17441692.2019.1611897

Barasa, E. W. (2015). Setting healthcare priorities in hospitals: a review of empirical studies. Health Policy and Planning, 30 (3). 386-96.

Barnabe, F., Guecini, J., and Di Perna, M. (2019). Assessing performance and value-creation capabilities in lean healthcare: insights from a case study. Public money \& management, 39(7). 503-11. Doi: 10.1080/09540962.2019.1598197. 
Baroudi, S., Tamim, R., and Hojeij, Z. (2020). A quantitative investigation of intrinsic and extrinsic factors influencing teachers' job satisfaction IN Lebanon. Leadership and policy in schools. Doi: $10.1080 / 15700763.2020 .1734210$

Chanda, U., and Goyal, P. (2020). A Bayesian network model on the interlinkage between socially responsible HRM, employee satisfaction, employee commitment and organisational performance. Journal of management analytics. 7(1). 105-38. Doi: $\underline{10.1080 / 23270012.2019 .1650670}$

Cwalina, W., and Drzewiecka, M. (2019). Who are the political leaders we are looking for? Candidate positioning in terms of leadership style. A cross-cultural study in Goleman's typology. Journal of political marketing, 18(4). 344-359. Doi: 10.1080/15377857.2019.1678908

Donkor, F., and Zhou, D. (2020). Organisational commitment influences on the relationship between transactional and laissez-faire leadership styles and employee performance in the Ghananian public sector environment. Journal of Psychology in Africa. 30(1). 30-36. $\underline{10.1080 / 14330237.2020 .1712808}$

Faiza , M., Longbao , W., Mohammad , N., and Qazi , A. S. (2019). The impact of transformational leadership on job performance and CSR as mediator in SMEs. Sustainability, 11(436). 1-14. Doi: $0.3390 / \mathrm{su} 11020436$.

Haase, H., and Franco, M. (2020). Leadership and collective entrepreneurship: evidence from the health care sector, innovation: The European journal of social science research, 33(3). 368385. Doi: 10.1080/13511610.2020.1756231

Hamstra, M.R.W., Van Vianen, A.E.M., and Koen, J. (2019). Does employee perceived personorganisation fit promote performance? The moderating role of supervisor perceived personorganisation fit. European journal of work and organisational psychology. 28(5). 594-601. Doi: 10.1080/1359432X.2018.1485734

Henricks, M.D., Young, M., and Kehoe, E.J. (2020). Attitudes toward change and transformational leadership: A 96longitudinal study. Journal of change management, 20(3). 202-219. Doi: $\underline{10.1080 / 14697017.2020 .1758529}$

Khuwaja, U. (2020). Leadership and employee attitudes: The mediating role of perception of organisational politics. Cogent Business and Management, 7(1). Doi: $10.1080 / 23311975.2020 .1720066$

Islam, M., and Rahman, M. (2020). Leadership styles navigate employee job performance. The Comilla University Journal of Business Studies, 5(1). 87-109.

Islam, M. S., Rahman, M., and Siddiqui, k. O. (2019). Styles of leadership navigate employee job performance. SSRN Electronic Journal, 5(1), 87-109. doi:10.2139/ssrn.3504262

Iqbal , N., Anwar, S., and Haider , N. (2015). Effect of leadership style on employee performance. Arabian Journal of Business and Management Review. 5. 1-6.

Langat, G., Linge, T., and Sikalieh, D. (2019). Effect of inspirational motivation on employee job performance in the insurance industry in Kenya. International Journal of Research in Business and Social Science, 8(6), 1-7.

Manzoor, F., Wei, L., Nurunnabi, M., and Subhan, A. Q. (2019). The impact of transformational leadership on job performance and CSR as mediator in SMEs. Sustainability. 11. 1-14.

Ministry of Health (2019). Annual health sector performance report. Financial year 2019/2020. Kampala.

Mishra, S.S. (2020). Do street-level bureaucrats exhibit transformational leadership for influencing sound governance and citizens' satisfaction? International journal of public administration. Doi: $\underline{10.1080 / 01900692.2020 .1765798}$

Mukundane, M., Nannungi, A., and Bataringaya, D. (2016). Assessing the management and administration in public health facilities of Uganda and the implications for the healthcare service delivery and utilisation. ACODE Policy Research Series.

Ngaithe, L., K'Aol, G., Lewa, P., and Ndwiga, M. (2016). Effect of idealized influence and inspirational motivation on staff performance in state owned enterprises in Kenya. European Journal of Business and Management, 8(30), 6-13.

Shahzad, U., Al-Noor, N.H., Hanif, M., and Sajjad, I. (2020). An exponential family of median based estimates for mean estimation with a simple random sampling scheme. Communications in statistics - Theory and methods. 1-10. Doi: 10.1080/03610926.2020.1725828 
Ohunakin, F., Adeniji, A.A., Oludayo, O.A., Osibanjo, A.O., Oduyoye, O.O. (2019).Employees' retention in Nigeria's hospitality industry: The role of transformational leadership style and job satisfaction. Journal of human resources in hospitality \& tourism. 18(4). 441-470. Doi: $\underline{10.1080 / 15332845.2019 .1626795}$

Oketch, B. (2019). Few personnel, absenteeism cripple Lira's health services. New Vision.

Vito, R. (2020). How do social work leaders understand and ideally practice leadership? Synthesis of core leadership practices. Journal of social work practice, 34(3). 263-79. 10.1080/02650533.2019.1665002

Wammy. (2014). The South Africa facilities management. South Africa: UNISA Press.

Zohra, K., Mukaram , A., and Syed, S. Z. (2018). Impact of transactional leadership and transformational leadership on employees performance: a case of FMCG industry of Pakistan. 8(3). 23-30. Retrieved on 15 Dec. 2020 from https://www.researchgate.net/publication/326131085 